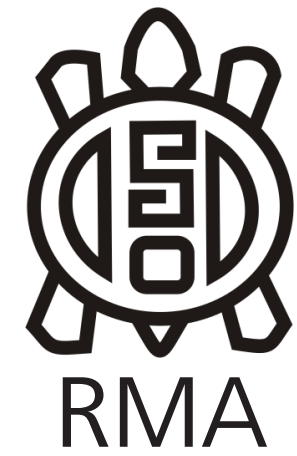

Arqueología

\title{
Mapa de potencial arqueológico de la Estancia Fortín Chacabuco (PNNH-APN): primeros resultados integrando información arqueológica, histórica, geomorfológica y ambiental
}

\author{
Map of archaeological potentiality of Estancia Fortín Chacabuco \\ (PNNH-APN): first results integrating archaeological, historical, \\ geomorphological, and environmental information
}

\author{
Marcia Bianchi Villelli*, Federico L. Scartascini*, \\ Emmanuel Vargas*, Ignacio Mizerit*, Maitén Di Lorenzo*, \\ Alhué Bay Gavuzzo*, Soledad Caracotche** y Adam Hajduk***
}

${ }^{*}$ CONICET - Instituto de Investigaciones en Diversidad Cultural y Procesos de Cambio (IIDyPCa)-Universidad Nacional de Rio Negro. E-mail: bianchi.marcia@gmail.com; fscartascini@gmail.com; femmanuelvargas@gmail.com;maiten.dilorenzo@gmail.com; ignaciomizerit@gmail.com; iidypca@unrn.edu.ar

**Dirección Regional Patagonia Norte - APN.E-mail: scaracotche@apn.gob.ar *** Museo de la Patagonia Francisco Moreno-Parque Nacional Nahuel Huapi-APN. E-mail: adamhajduk@bariloche.com.ar

\begin{abstract}
Resumen
Este trabajo presenta los primeros resultados de un proyecto interdisciplinario acerca del potencial arqueológico de la estancia Fortín Chacabuco, que conforma una primera instancia de construcción de una línea de base arqueológica en el Parque Nacional Nahuel Huapi (APN). La integración conjunta de información geoambiental, arqueológica e histórica, se utilizó como punto de partida para elaborar un mapa y jerarquizar el espacio en términos del potencial de uso humano. Los resultados iniciales permitieron relevar al menos cinco sitios arqueológicos y otros rasgos relevantes que indican que la ocupación humana de este sector del Parque Nacional fue heterogénea espacial y temporalmente. Estos resultados, además, constituyen los primeros antecedentes para formular un plan de manejo de patrimonio arqueológico en colaboración con la Administración de la Estancia Fortín Chacabuco y los profesionales del Parque Nacional Nahuel Huapi y la Dirección regional Patagonia Norte (APN).
\end{abstract}

Palabras clave: Norpatagonia; Holoceno tardío final; Fortin chacabuco, Parque Nacional Nahuel Huapi; Patrimonio arqueológico.

\begin{abstract}
This work presents the first results of an interdisciplinary project about the archaeological potentiality of the Fortin Chacabuco ranch, as the first instance in order to build an archaeological baseline in the Nahuel Huapi National Park (Nationals Parks Administration). The integration of geoenvironmental, archaeological and historical information was used as a starting point to elaborate a map and rank the space in terms of potential for human use. The initial results allowed to survey at least five archaeological sites and other relevant features that indicate that human occupation of this sector of the National Park was spatially and temporally heterogeneous. These results also constitute the first record to formulate an archaeological heritage management plan in collaboration with the Estancia Fortin Chacabuco administration and the Nahuel Huapi National Park and Nationals Parks Administration professionals.
\end{abstract}

Keywords: North-patagonia; Late final Holocene; Fortin chacabuco; Nahuel Huapi National Park; Archaeological heritage.

\section{Introducción}

Este trabajo es una investigación conjunta entre profesionales del Departamento de Conservación y Educación Ambiental del Parque Nacional Nahuel
Huapi (PNNH-APN), de la Dirección Regional Patagonia Norte (DRPN-APN) y del Instituto de Investigaciones en Diversidad Cultural y Procesos de Cambio (IIDyPCaUNRN-CONICET), con el fin de generar información de base y facilitar la toma de decisiones para la gestión del 
territorio, en el marco del Plan de Gestión 2019-2029 del Parque Nacional Nahuel Huapi - Administración de Parques Nacionales (APN 2019).

En este contexto, se propuso la realización de un "Diagnóstico de Potencial Arqueológico de la Ea. Fortín Chacabuco (Ea.FC)", como una estrategia de investigación-gestión del patrimonio. La estancia Fortín Chacabuco (en adelante Ea. FC), está ubicada en el Parque Nacional Nahuel Huapi (PNNH-APN) (Figura 1B) y en 2016 comienza a ser administrada por The Nature Conservancy (en adelante TNC), bajo un Plan de Manejo Integral (TNC 2016) dedicado a la gestión ganadera y de pastizales y cuenta con un laboratorio a cielo abierto conformado por diversas investigaciones interdisciplinarias. Si bien en el año 2017 el Lic. Adam Hajduk había realizado varios relevamientos en el área, no se había iniciado un estudio del patrimonio arqueológico de forma sistemática y en profundidad, permaneciendo como área de vacancia la evaluación y conservación del patrimonio histórico cultural del PNNH.

Desde la perspectiva arqueológica, la información de base se construye sobre las posibilidades para el uso humano del espacio, considerando en primer lugar, los escenarios geológicos, geomorfológicos y ambientales. En segundo lugar, sobre los antecedentes arqueológicos e históricos específicos de la zona, así como los procesos incipientes de urbanización -estancias, rutas y forestaciones- que pudieron haber afectado el registro. Los resultados obtenidos brindaron información para establecer criterios de conservación, definir el monitoreo de deterioro y/o destrucción de sitios arqueológicos, profundizar la investigación en la región, y desarrollar actividades de uso público-difusión y educación ambiental, en el contexto de un manejo sustentable y holístico (Savory 1999; Molinari et al. 2001).

En este trabajo presentamos el diseño metodológico empleado, los antecedentes arqueológicos e históricos para la microregión, los resultados de los primeros relevamientos arqueológicos, la revisión histórica y la información geomorfológica y ambiental. Los objetivos propuestos fueron, detectar el emplazamiento de sitios arqueológicos, establecer criterios de conservación, definir el monitoreo de deterioro y/o destrucción de los sitios ya conocidos y profundizar la investigación en la región.

\section{Antecedentes arqueológicos e históricos}

La estancia Fortín Chacabuco se encuentra en un contexto con una profundidad histórica muy significativa, la cual presenta, en un radio geográfico que no supera los 40 $\mathrm{km}$ lineales de la Ea., ocupaciones humanas tempranas desde 12.000 años antes del presente (AP en adelante) en el sitio El Trébol (éjido de Bariloche), con evidencias de poblaciones cazadoras recolectoras adaptadas al ecotono bosque-estepa (Albornoz y Hajduk 2006, 2008; Hajduk et al. 2008 y 2012). Dentro del PNNH, en la cuenca superior del río Limay, el sitio Arroyo Corral II fue fechado en 8000 años AP (Arias Cabal et al. 2011), en valles secundarios del río Limay, los abrigos rocosos de los sitios Cuyín Manzano y Cueva Traful I, se hallaron ocupaciones que rondan los 9000 años AP (Cevallos 1982; Silveira 2003; Silveira et al. 2010).

La secuencia estratigráfica de buena parte de estos sitios incluye también ocupaciones humanas situadas desde cerca de 5.000 años AP hasta momentos de producción alfarera (Vignati 1944; Cevallos 1982; Crivelli et al. 1993; Hadjuk et al. 2006; Silveira 2003; López et al. 2010; Silveira et al. 2010). En el límite Sur del PNNH, específicamente en la zona del valle inferior del río Manso, la presencia humana parece ser algo más tardía, hasta el momento el fechado más antiguo ronda los 8000 años AP (Fernández et al. 2013, 2019a). Ya para los 2000 años AP, las evidencias de ocupación humana se vuelven significativas a nivel regional. Durante este periodo se hallaron evidencias en la Isla Victoria de las poblaciones canoeras en Puerto Tranquilo I, que dominaban la circulación por el lago (Hajduk et al. 2018). Más tardíamente, también aparecen en la región las primeras evidencias de producción local y uso de alfarería (Hajduk et al. 2011). En el ejido de Bariloche se hallaron a su vez, varios sitios que por sus características en el arte rupestre y los conjuntos materiales recuperados, pueden ser relacionados a este momento, aunque aún no han sido fechados y/o publicados (Hajduk com. pers. 2017).

A fines del siglo XVII, se produjo la llegada de los españoles desde el reino de Chile con el avance misionero del Padre Mascardi y otros, para evangelizar a las poblaciones canoeras y cazadoras -nombradas puelches y poyas (Furlong 1963). En 1931, un aficionado, Carlos Ortiz Basualdo, excavó una parte de un cementerio que fue designado por Vignati (1936) como la misión de Nahuelhuapi dada su localización en Península Huemul; se hallaron también restos arqueológicos coloniales en la zona de Llao-Llao muy posiblemente asociados a la ocupación colonial jesuita (Hajduk et al. 2013; Caruso Fermé et al. 2018). Asimismo, en la zona del Manso hay evidencias de ocupaciones para los siglos XVII y XVIII, en este caso sin presencia de materiales europeos (Fernández et al. 2019b). De ahí en más, la presencia colonial primero y estatal después, fueron vinculándose de forma diversa con las poblaciones indígenas patagónicas, que se caracterizaban por su movilidad y redes de circulación e intercambio transcordilleranos. Durante el siglo XIX, las relaciones entre los pueblos indígenas y estado argentino fueron complejizándose entre tensiones y alianzas comerciales (Vezub 2009; Méndez 2010; Vezub y Mazzalay 2016).

En 1878, a partir de la Ley del Empréstito -947/1878- se 
modifica este escenario definitivamente. Al año siguiente el estado argentino al mando del General J. A. Roca avanzó sobre las poblaciones indígenas, este proceso de ocupación militar (1878-1885) produjo la matanza, desarraigo y desmarcación étnica de las poblaciones mapuche y tehuelche (Mases 2010; Bandieri 2012; Pérez 2016). En particular, en el marco de la Campaña de los Andes, el Fortín Chacabuco fue la avanzada militar más austral de los llamados fortines del desierto, fundado a fines de 1882. Desde allí se organizó la última partida del ejército en busca de los caciques Sayhueque, Inacayal y Foyel, siendo vencidos en la batalla de Apeleg (Chubut) en febrero de 1883; Sayhueque es finalmente tomado prisionero en 1885 en Genoa. Los destinos y trayectorias de los y las indígenas que sobrevivieron de ahí en más, fueron diversos: prisioneros trasladados a campos de concentración y a Buenos Aires, incorporación al ejército, al trabajo doméstico y como mano de obra rural en distintos lugares del país (Mases 2010; Delrío et al. 2018). Los tres caciques y sus familiares fueron apresados y llevados al Museo de la Plata para trabajar en mantenimiento, ser estudiados y exhibidos por la ciencia tanto en vida, como una vez muertos (Oldani et al. 2010).

Las consecuencias de la avanzada del ejército en norpatagonia implicaron la definición de las fronteras estatales, la reorganización administrativa y poblacional, relocalizando población rural indígena y criolla a la vez que recibía a migrantes europeos y chilenos en menor medida (Navarro Floria y Vejsbjerg 2009). Así se conformaron las estancias que comienzan a articular la colonia con la producción ganadera, siendo las tierras de la zona entregadas a distintos propietarios privados. En ese contexto, la Ea. FC pasó a ser propiedad de la familia Newbery hasta 1946, por su cercana relación con el General Roca (Guzmán 2009).

Las oscilaciones de la dinámica de intercambio comercial con Chile marcaron las primeras décadas del siglo XX (Méndez, 2010; Blanco 2012), hasta 1922, que la llegada del Parque Nacional del Sur vuelve a reorganizar el territorio (Bessera 2008). Hoy en día, la Ea. FC es una de las tantas propiedades dentro del mosaico de diversidad que es el PNNH. Luego de una historia de ventas y sucesiones, en 2016 gracias a una donación parcial de los propietarios, se consolida un consorcio para administrar Ea. FC entre TNC y la APN, con el fin de abordar este "espacio como un laboratorio a cielo abierto para la investigación orientada a la producción sostenible" (TNC 2016:5).

\section{Metodología}

La propuesta en esta instancia no se focalizó en el estudio de un sitio, un período temporal ni un tipo de registro, sino que buscó establecer el mapa de señal arqueológica para el área. Así, el diseño metodológico incluyó tres etapas. La primera fue generar una estratificación del área de la Ea.FC en un entorno SIG, vinculando tres cuerpos de evidencia, la información geoambiental, la documental/bibliográfica y la arqueológica (ver abajo), y diseñar, a partir de esto, los esquemas de relevamiento y prospecciones para cada sector (Figura 1A). La segunda etapa fueron los relevamientos en sí y su procesamiento en un mapa de potencial arqueológico. La tercera etapa fue la producción de criterios de monitoreo y manejo de la estancia en conjunto con la DRPN-APN y la administración de la estancia, lo cual excede los fines de este trabajo (ver Bianchi Villelli y Scartascini 2020).

\section{Información Geo-ambiental}

La información geo-ambiental permitió la segmentación del paisaje en función de las distintas geoformas con el fin de jerarquizar los sectores según el uso humano posible y los procesos postdepositacionales que podrían afectar a las muestras, definiendo la segmentación del espacio para las prospecciones arqueológicas. Se incluyó también una línea de trabajo exploratoria a partir de la Banda $L$ del Saocom 1A, que ya ha dado resultados en arqueología dada su posibilidad de penetrar la superficie detectando rasgos y estructuras enterradas (Lasaponara y Masini 2013).

\section{Información Histórica}

La compulsa documental y bibliográfica precisó la historia reciente de la estancia, revisando las versiones historiográficas al respecto. Se indagó en fuentes inéditas, éditas, cartografías históricas y fotografías en diversos archivos: el Archivo General de la Nación, el Departamento Gestión Documental -Dirección Prov. de Catastro e Información Territorial de la Provincia de Neuquén-, Servicio Histórico del Ejército (Buenos Aires), y Museo de la Patagonia F. P. Moreno (MP-PNNH-APN). Se digitalizaron piezas documentales inéditas como la libreta de campo del Coronel Villegas de 1882/1883 (MPPNNH) y el mapa de relevamiento de Encina y Moreno y su expediente asociado de 1884 (DPCelT).

\section{Información Arqueológica}

El trabajo arqueológico implicó varias etapas. En primer lugar, la revisión detallada de antecedentes en función de contextualizar el territorio de la estancia en el contexto de las ocupaciones humanas de los últimos 10.000 años en el área del lago Nahuel Huapi. Estos sitios previamente conocidos fueron evaluados en función de su ubicación -distancia con relación a la estancia-, de su emplazamiento -lugar/ambiente/geoforma-, las condiciones de ocupación y la visibilidad y preservación diferencial. Estos datos se complementaron con los relatos orales sobre la ocurrencia de hallazgos aislados, y con la búsqueda de fotografías aéreas, satelitales y de radar.

Considerando la diversidad en las unidades ambientales, las expectativas arqueológicas y los usos informados por la Estancia, se realizaron transectas georreferenciadas 

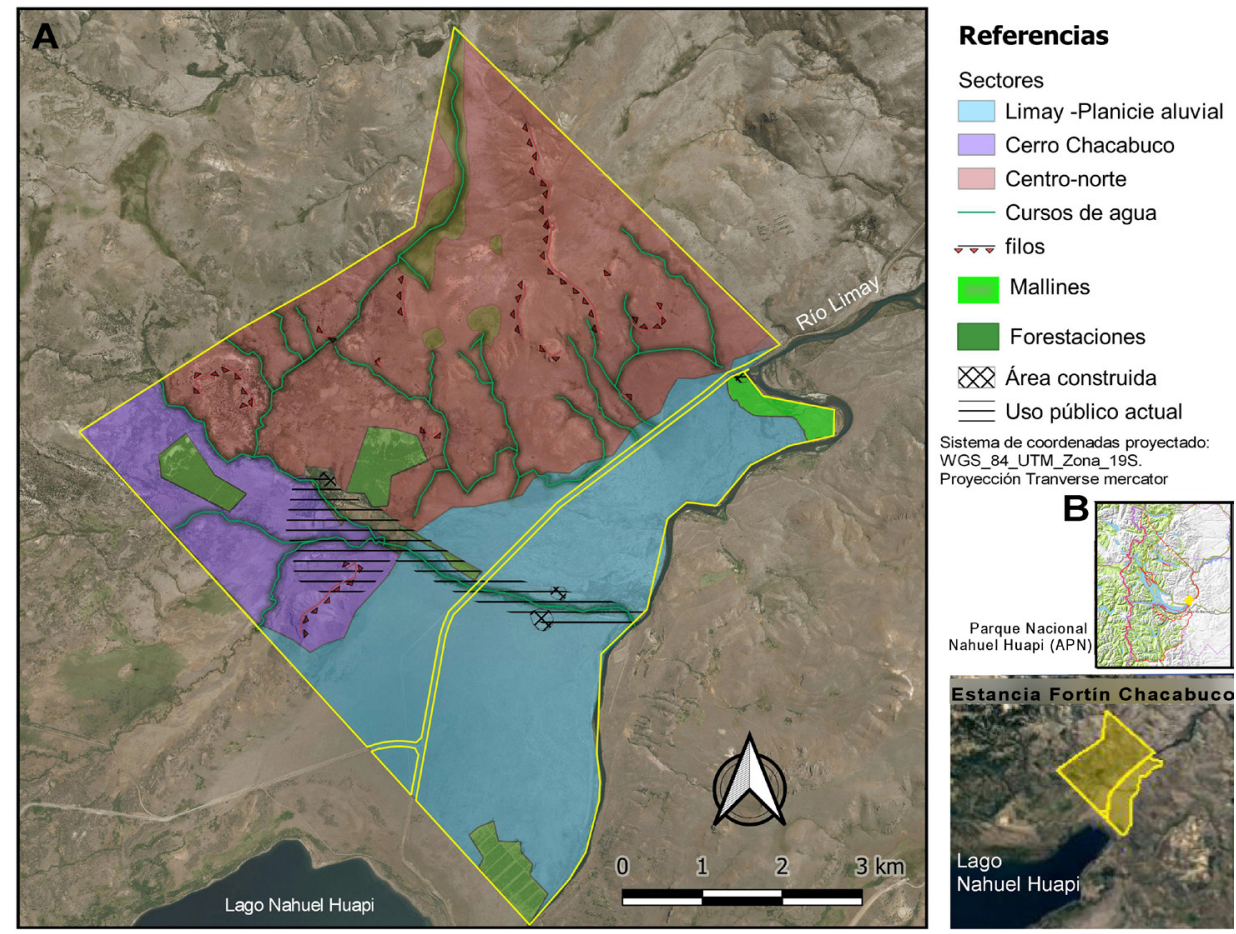

Figura 1. A: Estratificación de la Ea. Fortín Chacabuco en función de la información geo-ambiental, los antecedentes arqueológicos e históricos de la región, y los usos actuales de la estancia. Se detallan los sectores mencionados en el texto. B. Localización de la estancia en el Parque Nacional Nahuel Huapi y abajo, detalle del área.

Figure 1. A: Stratification of Ea. Fortín Chacabuco based on the geo-environmental information, archaeological and historical background of the region, and the current uses of the ranch. The sectors mentioned in the text are detailed. B. Location of the ranch in the Nahuel Huapi National Park and below, area detailed.

sistemáticas y asistemáticas, estimando $5 \mathrm{~m}$ de ancho por operador. Las transectas sistemáticas, realizadas en el sector Este de la estancia, implicaron barridos de $1000 \mathrm{~m}$ con cobertura de entre 30 y $50 \mathrm{~m}$, y estaciones de registro cada $100 \mathrm{~m}$ donde se completaron fichas de registro de superficie, cubriendo $8.700 \mathrm{~m}^{2}$. Las transectas asistemáticas tuvieron, debido al terreno más escarpado y a rasgos específicos, relevamientos más intensivos, y cubrieron $571.515 \mathrm{~m} 2$. El área total cubierta por transectas tanto sistemáticas como asistemáticas fue de $580.235 m^{2}-116.047 m$ lineales.

En los sectores con mayor densidad de hallazgos y en las localizaciones descriptas en los documentos históricos, las tareas exploratorias incluyeron la excavación de sondeos, pruebas de pala y el levantamiento de perfiles. Las transectas asistemáticas, se realizaron principalmente en el sector Oeste, siguiendo geoformas o rasgos específicos del paisaje como valles, arroyos, filos y mallines, con especial atención a la presencia de aleros o abrigos rocosos que pudieran contener material arqueológico. En el sector del cerro Fortín Chacabuco, el relevamiento fue más intensivo, incluyendo transectas sistemáticas en la planicie aluvial actual, el barrido con el detector de metales, la excavación de sondeos, pruebas de pala y el levantamiento de perfiles, en función de la señalización por testimonios orales como una zona de hallazgos de materiales y por ser el área potencial de emplazamiento del sitio histórico.

La segunda etapa consistió en los relevamientos que incluyeron el tipo de registro y su estado de conservación, aspectos geomorfológicos, los riesgos en términos de su investigación y preservación atendiendo al plan de manejo y el uso público de la estancia. El resultado integrado fue el mapa de potencial arqueológico de la estancia (Figura 6). Por último, se discutieron y definieron criterios de monitoreo de los sitios, así como de actividades futuras, en función de la sensibilidad arqueológica del área. Se evaluó esta metodología de modo tal que se constituya como referencia para extender a otros sectores del PNNH; se atendió a la evaluación de la efectividad y los resultados obtenidos, coordinando la producción de la información con el Reglamento para la Conservación del Patrimonio Cultural en Jurisdicción de la APN (2001) así como su ingreso en el Registro Nacional de Recursos Culturales (RC).

\section{Resultados: mapeando el potencial arqueológico de la Estancia Fortín Chacabuco}

Los trabajos de campo realizados permitieron prospectar, de forma sistemática o asistemática, el $75 \%$ del total de los sectores estratificados (Figura 3A); los sectores restantes fueron pospuestos debido a las restricciones sanitarias impuestas en el marco del COVID19 en marzo de 2020. A pesar de esta limitación imponderable, el relevamiento alcanzado permitió cubrir la totalidad de las unidades ambientales disponibles, por lo que consideramos que los resultados obtenidos son representativos para toda la estancia.

El mapa geomorfológico de la estancia (Figura 2) permitió abordar más específicamente las condiciones de depositación de contextos arqueológicos puntuales; su trabajo implicó la teledetección ${ }^{1}$ y la salida a campo

\footnotetext{
1 Para el mismo se empleó un modelo de elevación digital (DEM) de $12.5 \mathrm{~m}$ de resolución obtenido de https://search.asf.alaska.edu/\#/ y un mosaico fotogramétrico de $1.38 \mathrm{~m}$ de resolución con imágenes obtenidas de bing.com/maps.
} 


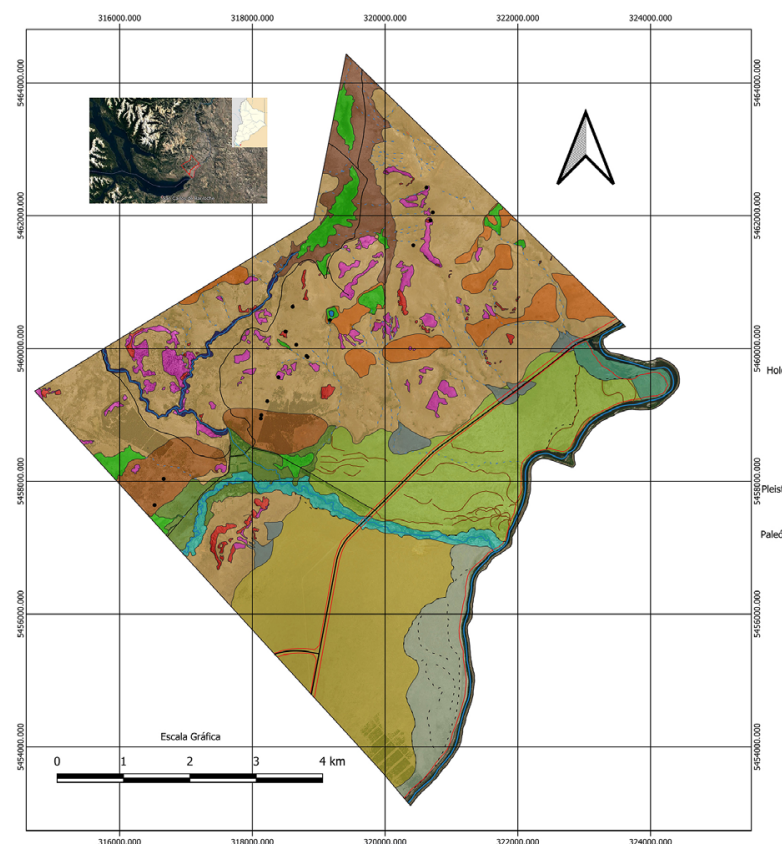

Figura 2. Mapa geomorfológico del Estancia Fortín Chacabuco (PNNH-APN).

Figure 2. Geomorfological map of Estancia Fortín Chacabuco (PNNH-APN).

en conjunto con el equipo de arqueólogos, lo que permitió resolver temáticas específicas de importancia arqueológica como la evaluación de condiciones de preservación y monitoreo de varios de los sitios. Se iniciaron también relevamientos geológicos en función de abordar posteriormente la disponibilidad de materias primas líticas.

El relevamiento arqueológico implicó la georreferenciación de los sitios ya conocidos y de los nuevos contextos registrados. Se mapearon agentes activos y factores de riesgo en términos de preservación, abordando distintas escalas de trabajo en función de las recomendaciones por tipo de uso del territorio y para establecer monitoreos futuros para la estancia. Los hallazgos, el estado de conservación y las medidas de manejo fueron informadas a la APN (PNNH y DRPN). A continuación, detallamos cada uno de los sectores en los que se fue organizando el relevamiento (ver Figura 1A, 3A).

\section{Sector Limay}

Este sector comprende los cuadros entre la ruta nacional (RN) 237 y el río Limay, siendo parte de la planicie glacifluvial de pendiente plana asociada a las morenas frontales que limitan el lago Nahuel Huapi. Sobre la margen oeste del río Limay, esta planicie está disectada por antiguas terrazas que evidencian la modificación del curso y la profundización hasta su cauce actual. En las prospecciones al Norte del arroyo Chacabuco, los depósitos glacifluviales continúan, pero son sepultados por depósitos de origen fluvial correspondientes

Mapa Geomorfológico Estancia Fortín Chacabuco

Referencias Geomorfológicas

- Antiguos cauces fluvialts

Terrazas Fluviales

7 Mallin morologicas

Relieve de denudación
Depósitos aluvio-coluvites
Abanico Alurial

7 Depósitos rí Limar

Fondo de valle

Planiciel aluvial $A^{\circ}$ Chacabuco
Planicie alluvial antigua $A^{\circ}$ Chacab

Planicie allwiel antigua $R^{\circ}$ Limay

Planicie glacinuvial cubierta por depóstos aluviales más modernos

Planicie Glacififuvial
Complejo Morénico

Complejo Morénico
Depósitos morénicos aterrazados

Afforamiento rocoso de escaso desarrollo vertical
Aforamiento rocoso

Referencias Geográficas

-... Arroyos Intermitertes

- Arroyos Inte

- Rros Principales

- caguninos de le estan

$\square$ Lúmites estancia Fortin Chaccabuco

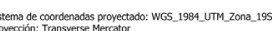

Puyehue en 2011. En las transectas sistemáticas realizadas no se detectaron evidencias arqueológicas, pero se localizaron algunos rasgos actuales -el viejo obrador de la ruta y la cantera abandonada- que condicionaron la conservación y preservación potencial del registro arqueológico.

\section{Sector Cerro Chacabuco}

Este sector corresponde al cuadro Fortín. En su lado Este, presenta una continuidad geomorfológica con la planicie glacifluvial antes mencionada. El extremo Sur-Oeste de la estancia se caracteriza por la presencia de los cursos del arroyo Chacabuco hacia el Sur, y el Newbery hacia el Oeste; y por un relieve de denudación y depósitos aluvio-coluviales. En esta área se ubica una de las forestaciones de mayor superficie. En el Suroeste del cuadro se encuentra el Cerro Chacabuco, cordón de rumbo aproximado NE-SO con una altura máxima de 1037 msnm. Se caracteriza en su parte Sur por la presencia de lavas y depósitos piroclásticos estratificados -andesitas/basaltos y brechas- y al Norte, por la presencia de un domo de composición ácida, posiblemente riodacítica, y una serie de alineaciones verticales, sobre las cuales se encuentran los aleros 1, 2 y la cueva 1 -estos tres sitios fueron detectados previamente, aunque no fueron relevados en esa instancia de manera sistemática ni informados al PNNH, ni publicados-.

Hacia el Norte del cuadro, está la planicie de inundación del arroyo Chacabuco, donde se ha observado una terraza antigua más elevada y con antiguos cauces y meandros; esta geoforma incluye en su lado Oeste la confluencia con la planicie aluvial del arroyo Newbery. Se observan también depósitos aluviales actuales, que alcanzan unos $300 \mathrm{~m}$ de ancho y que presentan antiguos meandros cuyas orillas se encuentran vegetadas. Con excepción de los sitios descriptos a continuación, en las 


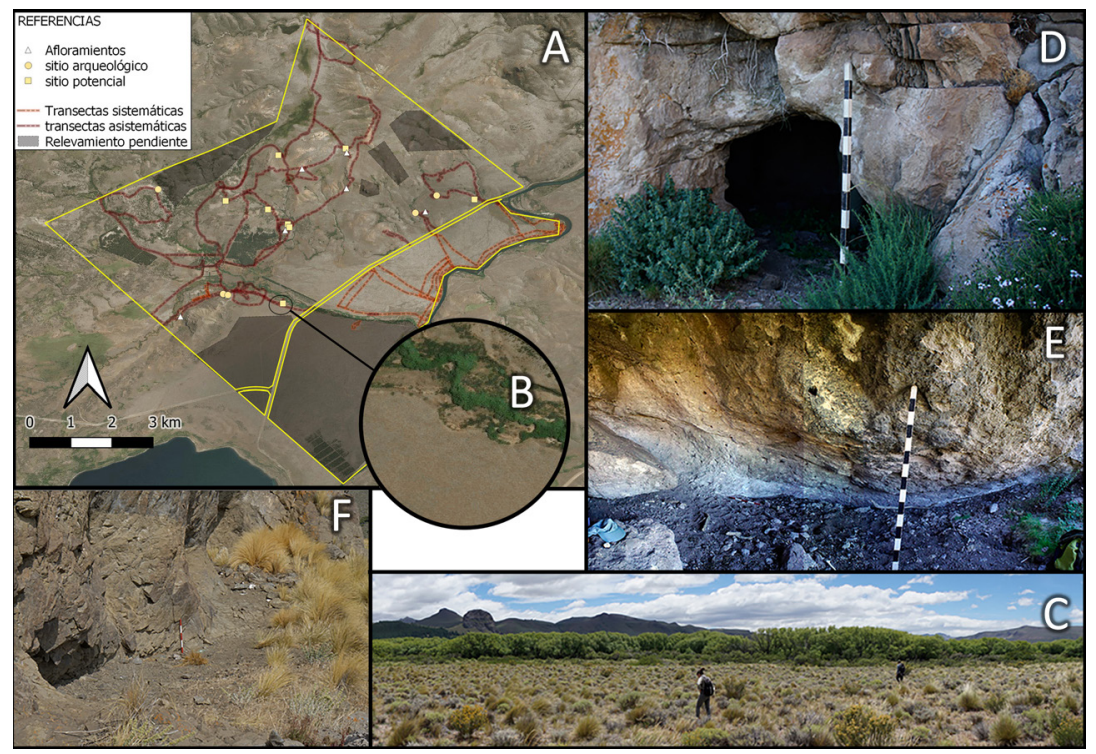

Figura 3. A: Mapa de las prospecciones realizadas y las evidencias arqueológicas halladas. B: Detalle de la imagen satelital del sector identificado para el Fortín Chacabuco. C: prospecciones en el sector del Fortín. D. Entrada de la Cueva 1. E: Interior de la Cueva 2. F: Alero 3, vista SE.

Figure 3. A: Map of surveys carried out and archaeological evidence found. $B$ : Detail of the satellite image of the sector identified for Fortin Chacabuco. C: prospects in the Fortín sector. D. Entrance of Cueva 1. E: Interior of Cueva 2. F: SE view of Alero 3.

prospecciones hubo escasas evidencias arqueológicas. En el área circundante al cerro, las transectas superficiales asistemáticas, los sondeos en un montículo y el barrido con el detector de metales en la antigua llanura de inundación arrojaron resultados negativos. No obstante, estos relevamientos re-ubicaron los sitios previamente descriptos (alero 1, 2 y cueva 1) en el cerro, descartando la presencia de otros aleros y/o cuevas; a continuación, los describimos.

La cueva 1 se ubica a unos $4 \mathrm{~m}$ por delante del alero 1 (ver más abajo), sobre la pendiente acentuada del talud rocoso - ca. $30^{\circ}$-, conformado por depósitos de un cono de deyección en dirección Norte. La cueva es parte de un afloramiento de rocas ácidas porfíricas y presenta abrigo interior de 3,7 $\mathrm{m}$ de largo, $3 \mathrm{~m}$ de ancho y 1,5 $\mathrm{m}$ de alto; su boca de entrada es estrecha -1,6 ms- $y$ presenta orientación Norte (Figura 3D). En su interior se identificó sólo la presencia en superficie de escasos restos óseos faunísticos en estado fresco, presuntamente actuales. En cambio, en el exterior se hallaron materiales arqueológicos distribuidos en superficie, desde la entrada hasta 1,4 m sobre una pequeña explanada del talud que funciona como acceso a la cueva. Esta área forma parte del recorrido de bajada de una picada desde el alero 1, que rodea la cueva desde el Oeste, continuando el descenso hacia el Este. El accionar de los animales que se resguardan en los reparos rocosos, así como la visita por contingentes de turistas, profundiza la re-exposición de los materiales y rodamiento de los clastos del talud, motivo por el cual se realizó la recolección superficial de los materiales (faunísticos $n=93$; humanos $n=1$; cuentas $\mathrm{n}=3$ ) y el rescate de los restos expuestos sobre uno de los perfiles del talud con riesgo de derrumbe (faunísticos $n=$ 2; humanos $n=5$; cuentas $n=1$ ). ${ }^{2}$

2 El análisis arqueofaunístico y bioarqueológico incluyó la identificación anatómica y taxonómica a partir de muestras comparativas de las colecciones óseas del IIDyPCa y el laboratorio de arqueología y etnohistoria PNNH-APN y atlas osteológicos de referencia (Bustamante
En la muestra faunística identificada de superficie $(\mathrm{NISP}=87)$ predominan los especímenes de mamíferos $(98,8 \%)$ y en menor proporción los de aves (1,2\%). Entre los primeros se identificó la presencia de especies autóctonas (67,8 \%) e introducidas (32,2 \%) -Tabla 1-. Una parte importante de este conjunto (74,2 \%) fue recuperado en una madriguera emplazada en el lado Oeste de la pared exterior de la cueva, así como las dos egagrópilas. La desagregación de una de estas permitió identificar restos de aves pequeñas, posiblemente passeriformes (NISP=13, NMI=1).

El análisis tafonómico de la muestra de superficie mostró, en términos generales, escasas evidencias de enterramiento, marcas de raíces $(9,7 \%)$ y depositaciones de carbonato de calcio $(1,1 \%)$ y óxido de manganeso (15, $1 \%)$, mientras que las evidencias de exposición superficial son más abundantes, blanqueamiento (41,9\%) y meteorización (38,7\%), incluyendo estadios mayores o iguales a $3(n=5)$. Asimismo, se registró un espécimen de vizcacha con marcas de incisivos de roedor, dos con evidencias de corrosión digestiva (liebre europea y micromamífero) y siete con diversas marcas de dientes de carnívoros (scores, punctures, pitts, pitting y furrowing), entre los que se identificaron restos de vizcacha $(n=3)$, liebre europea $(n=1)$ y oveja $(n=1)$. Del total del conjunto, 32 especímenes fueron considerados modernos, por presentar restos de tejido blando.

Por último, entre los materiales óseos de superficie (Tabla 1) se halló un espécimen de Homo sapiens correspondiente a un peroné, con marcas de raíces y depositaciones de manganeso, así como blanqueamiento y avanzado estadio de meteorización. A dos metros de este hallazgo se registró el conjunto óseo en un perfil

y Saldivia 2018; Fernández et al. 2011). Para el análisis cuantitativo se emplearon las propuestas de Grayson (1984); Lyman (2008); y para los tafonómicos los lineamientos de Behresmeyer (1978) y Gutiérrez (2004) 


\begin{tabular}{|c|c|c|c|c|c|c|c|c|c|c|c|c|c|}
\hline & & TAXA & NISP & $\begin{array}{l}\text { NISP } \\
\%\end{array}$ & Met & Blanq & Raices & $\mathrm{CaCo3}$ & $\begin{array}{c}\mathrm{Mn} 0 \\
2\end{array}$ & Carnívoro & Roedor & Corr & $\mathrm{MNI}$ \\
\hline \multirow{17}{*}{ 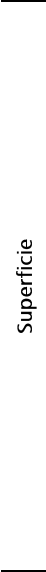 } & \multirow{13}{*}{ 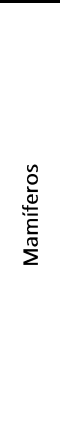 } & Homo sapiens & 1 & 1,1 & 1 & 1 & 1 & 0 & 1 & 0 & 0 & 0 & - \\
\hline & & Equus sp. & 1 & 1,1 & $x$ & $\mathrm{x}$ & 0 & 1 & 0 & 0 & 0 & 0 & 1 \\
\hline & & Ovis aries & 1 & 1,1 & 1 & 1 & 0 & 0 & 0 & 1 & 0 & 0 & - \\
\hline & & $\begin{array}{l}\text { Mammalia indet. } \\
\text { (mediano) }\end{array}$ & 15 & 17,0 & 12 & 12 & 0 & 0 & 5 & 1 & 0 & 0 & - \\
\hline & & Lycalopex sp. & 1 & 1,1 & 1 & 1 & 0 & 0 & 0 & 0 & 0 & 0 & 1 \\
\hline & & Lepus europaeus & 17 & 19,3 & 4 & 9 & 5 & 0 & 5 & 1 & 0 & 1 & 5 \\
\hline & & $\begin{array}{l}\text { Rodentia indet. } \\
\text { (grande) }\end{array}$ & 1 & 1,1 & 1 & 1 & 0 & 0 & 0 & 0 & 0 & 0 & - \\
\hline & & Lagidium sp. & 35 & 39,8 & 6 & 5 & 3 & 0 & 2 & 27 & 1 & 0 & 2 \\
\hline & & $\begin{array}{l}\text { Mammalia indet. } \\
\text { (chico) }\end{array}$ & 7 & 8,0 & 0 & 3 & 0 & 0 & 0 & 0 & 0 & 1 & - \\
\hline & & Octodontidae indet. & 1 & 1,1 & 0 & 0 & 0 & 0 & 0 & 0 & 0 & 0 & 1 \\
\hline & & Cricetidae indet. & 4 & 4,5 & 0 & 1 & 0 & 0 & 0 & 0 & 0 & 0 & 2 \\
\hline & & Sigmodontinae indet. & 2 & 2,3 & 0 & 2 & 0 & 0 & 0 & 0 & 0 & 0 & - \\
\hline & & Loxodontomys sp. & 1 & 1,1 & 0 & 0 & 0 & 0 & 0 & 0 & 0 & 0 & 1 \\
\hline & \multirow[t]{4}{*}{ Aves } & $\begin{array}{l}\text { Charadriiformes } \\
\text { indet. }\end{array}$ & 1 & 1,1 & 0 & 0 & 0 & 0 & 0 & 0 & 0 & 0 & 1 \\
\hline & & NISP & 88 & 100,0 & 25 & 35 & 8 & 1 & 12 & 30 & 1 & 2 & 15 \\
\hline & & NUSP & 6 & - & 4 & 4 & 1 & 0 & 1 & 1 & 0 & 0 & - \\
\hline & & NSP & 94 & - & 29 & 39 & 9 & 1 & 13 & 31 & 1 & 2 & - \\
\hline \multirow{5}{*}{ 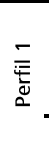 } & \multirow{5}{*}{ 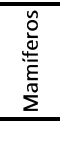 } & Homo sapiens & 3 & 42,9 & 2 & 2 & 3 & 0 & 2 & 0 & 0 & 0 & 1 \\
\hline & & cf. Homo sapiens & 2 & 28,6 & 0 & 0 & 2 & 0 & 1 & 1 & 0 & 0 & - \\
\hline & & Ovis aries & 1 & 14,3 & 1 & 1 & 0 & 0 & 0 & 0 & 0 & 0 & 1 \\
\hline & & Sigmodontinae indet. & 1 & 14,3 & 0 & 0 & 1 & 0 & 1 & 0 & 0 & 0 & - \\
\hline & & NISP & 7 & 100,0 & 3 & 3 & 6 & 0 & 4 & 1 & 0 & 0 & 2 \\
\hline
\end{tabular}

tres en la entrada de la cueva y una en el perfil $1^{3}$. De acuerdo con Karklins (2012), son cuatro cuentas simples monocromas según la Figura 4A: e-tubular mediana blanca opaca de $5 \times 3,3 \mathrm{~mm}$; f- circular aplastada chica blanca opaca de $3,5 \times 2 \mathrm{~mm}$; g- tubular mediana turquesa opaca de 4,2×3,2mm; tubular redondeada turquesa opaca de $3,2 \times 2,8 \mathrm{~mm}$. Si bien se hallaron en el mismo depósito superficial que contenía restos óseos humanos, según la coloración y morfología que presentan, no es posible determinar a priori el origen,

Tabla 1. Representación taxonómica de los conjuntos de superficie y del perfil 1 . Se indican las variables tafonómicas relevadas. Ref.: Met: meteorización; Blanq: blanqueamiento; Raíces: marcas de raíces; $\mathrm{CaCo3}$ : carbonato de calcio; $\mathrm{MnO2}$ : manganeso; Carnívoro: marcas de carnívoro; Roedor: marcas de roedor; Corr: corrosión digestiva.

Table 1. Taxonomic representation of the surface and profile 1 sets. The taphonomic variables surveyed are indicated. Ref.: Met: weathering; Blanq: whitening; Raíces: root marks; CaCo3: calcium carbonate; MnO2: manganese; Carnivoro: carnivore markings; Roedor: rodent marks; Corr: digestive corrosion.

natural $(n=7)$, conformado por tres especímenes de $H$. sapiens -una diáfisis de tibia, una falange medial y un metatarso completos-, dos elementos determinados como posibles $H$. sapiens -un fragmento de costilla y otro proximal de metatarso (Figura 4A)-, y dos fragmentos faunísticos.

Los restos humanos presentan marcas de raíces $(n=5)$ y depositaciones de óxido de manganeso $(n=3)$, mientras que el blanqueamiento y la meteorización se presenta de manera muy escasa y leve $(n=2)$. Es destacable que el espécimen de tibia de $H$. sapiens presenta estos efectos tafonómicos de manera inestable, las depositaciones de manganeso, blanqueamiento y meteorización se localizan en el sector proximal -sector expuesto-, el sector medial y distal presenta coloración natural -sector enterrado-, y las marcas de raíces se distribuyen de manera homogénea sobre toda la superficie cortical, lo cual permite inferir su re-exposición luego de haber estado enterrado, posiblemente a causa de a lgún agente natural, como por ejemplo pisoteo de ganado ovino, acción de zorros o remoción por gravedad (agentes detectados en el sitio) (Figura 4A:D). Asimismo, en el fragmento proximal de metatarso se registraron marcas de carnívoros (punctures) sobre ambos extremos (Figura 4A:C).

Por último, las cuentas de vidrio $(n=4)$ fueron halladas uso específico, ni el marco cronológico de estas piezas ya que presentan una amplia distribución espacial y temporal (Kidd y Kidd 1983; Hajduk 1982,1991). Siguiendo otros trabajos (Tapia y Pineau 2013; Bandama et al. 2018, entre otros), se realizarán estudios arqueométricos en CAB-CNEA sobre composición elemental y aspectos de manufactura que permitan acotar el rango temporal de producción de las mismas.

El Alero 1 tiene $7 \mathrm{~m}$ de largo y 3,95 $\mathrm{m}$ de ancho y orientación Norte. Se trata de un reparo rocoso cuya litología predominante son rocas ácidas porfíricas con la presencia de brechas volcánicas. El domo que conforma el afloramiento se encuentra pseudo-estratificado, uno de estos planos parece conformar el límite del techo de la cueva 1. Si bien en las prospecciones no se detectaron materiales arqueológicos en superficie, si se detectaron vetas basálticas, que potencialmente podrían haberse usado como materias primas líticas para la talla. Asimismo, se observó la presencia de ganado ovino, que afecta sus paredes con el roce, lo cual puede considerarse un problema potencial para la conservación de los paredones.

El Alero 2 tiene $10 \times 2,5 \mathrm{~m}$. y se ubica en el fondo del valle, al pie del talud (a aproximadamente $85 \mathrm{~m}$. de la cueva 1). Se encuentra sobre la base del cuerpo intrusivo ácido que aflora en el extremo NO del cerro. La laminación de la roca favorece el desarrollo de fracturas que generan una meteorización por descascaramiento favoreciendo la caída de rocas, lo que provoca riesgos de caída sobre el panel con pinturas rupestres (ver más abajo) y dificulta la preservación de las pinturas realizadas sobre el afloramiento.

Dentro del alero, se ubica un solo panel rupestre con una superficie de 1,97 $\mathrm{m}^{2}$. Este panel presenta una superficie

3 El Lic. Adam Hajduk halló una cuenta turquesa en este sector en el año 2017, sumando cinco en total. 


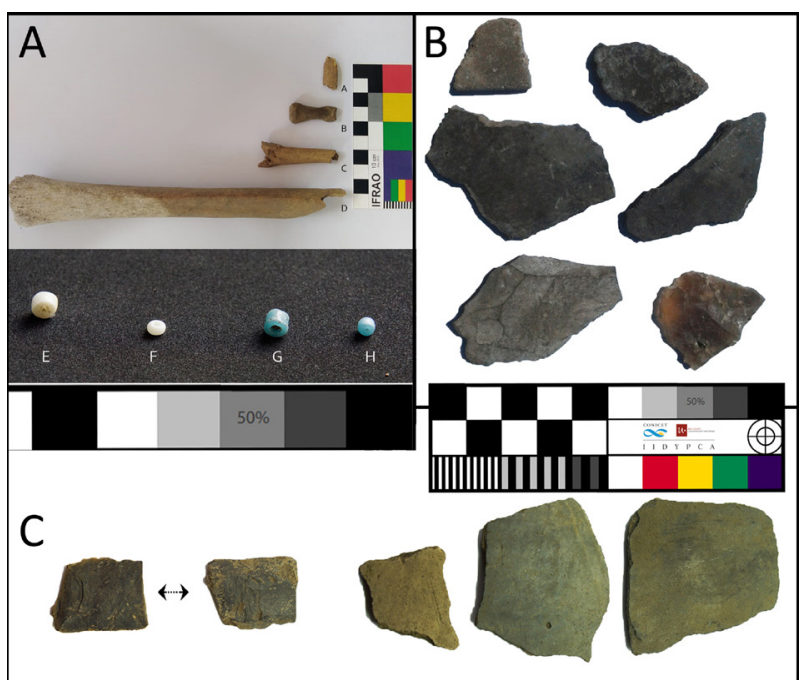

Figura 4. Materiales arqueológicos recuperados. A: Sector Cerro Chacabuco Cueva 1- arriba, restos óseos humanos (A: costilla indet., B: falange medial, C: metacarpiano/metatarsiano, D: diáfisis tibia izquierda) y abajo, cuentas vítreas. B: Sector Centro Norte Cueva 2- arriba fragmentos (4) de tiestos cerámicos de manufactura local, abajo 2 desechos de talla lítica (Izquierda: lasca basáltica de roca de grano fino oscuro; derecha: lasca lítica de roca silícea). C: Sector Centro Norte Alero 3 - izquierda, vista dorsal y ventral de lasca lítica de roca de grano fino oscuro, derecha: fragmentos (3) de tiestos cerámicos de manufactura local.

Figure 4. Recovered archaeological materials. A: Cerro Chacabuco sector Cueva 1- above, human bone remains ( $A$ : indet rib, B: medial phalanx, C: metacarpal / metatarsal, D: left tibia shaft) and below, vitreous beads. B: North Central Sector Cueva 2- above fragments 4 of ceramic sherds, below 2 lithic-cut debris (Left: basalt flake of dark fine-grained rock; right: lithic flake of siliceous rock). North Central Sector C: Alero 3 - left, dorsal and ventral view of lithic rock flake of dark fine grain, right: 3 fragments ceramic sherds.

regular y homogénea circunscrita espacialmente por determinados accidentes micro-topográficos y una única orientación (Hernández Llosas 1985). Las pinturas se localizan en el sector central del panel y cuenta con motivos de color rojo, con un alto grado de desvaído; esto puede deberse a las acreciones producto de los diferentes procesos bióticos y abióticos sufridos en la roca soporte, y que se han identificado en diversos sitios del área (Rousaki et al. 2018), así como también de factores antrópicos debido al tránsito humano y del pastoreo ovino en este sector en particular. Si bien no se observaron fogones actuales, en el sector superior inmediato a las representaciones rupestres se registraron restos de tiznado sobre el techo del abrigo, siendo necesario evaluar su posible correspondencia en el depósito con un fogón arqueológico, dado que se hallaron en superficie escasos materiales faunísticos y líticos termoalterados.

A partir del procesamiento de las fotografías mediante el plug-in DStretch (Harman 2008) se identificaron un total de nueve motivos de las pinturas distribuidos en tres micro sectores. Comenzando la descripción de izquierda a derecha (Figura 5), se encuentra el motivo $N^{\circ} 1$ : de difícil observación en función de sus condiciones de preservación que podría vincularse con una morfología similar a una clepsidra de cuerpo lleno. En el segundo micro sector, se registraron los motivos desde el $\mathrm{N}^{\circ} 2$ al $\mathrm{N}^{\circ} 6$, en lo que se ha considerado como una misma unidad de ejecución. Dentro de este micro sector se identificaron cuatro pisadas de tridígitos -asignables posiblemente al choique-, alineadas de forma vertical y dispuestas de forma sucesivas, en lo que comúnmente se ha denominado "rastros de pisadas". Sobre el comienzo de estos motivos en el sector inferior, se identificó el motivo $\mathrm{N}^{\circ} 6$ : un cruciforme escalonado con escaso rigor geométrico y trazo de ancho variable. Esta característica bien puede deberse a la acreción de una fina capa de color blanquecina producto de la degradación mineral de la roca soporte posterior a la ejecución del motivo.

El Fortín Chacabuco (FC) se instaló en el área como parte de la expansión del ejército argentino sobre los territorios de los pueblos indígenas patagónicos a fines del siglo XIX. La sistematización interdisciplinaria de los antecedentes permitió concentrar la información histórica dispersa, generar expectativas arqueológicas para detectar restos del fortín, así como prevenir posibles daños y definir marcos de referencia para el uso público de la estancia.

La localización del FC pudo ser definida a partir del relevamiento de 1883 que realizaron los agrimensores Carlos Encina y Edgardo Moreno; es la documentación más precisa y coherente ya que realizaron las primeras mediciones y triangulaciones topográficas de la época. ${ }^{4}$ Si bien el plano es sumamente interesante por toda la información plasmada (ver Bianchi Villelli y Scartascini 2020), es en el texto que se menciona de forma precisa la ubicación del sitio, a unos 2500 m del Limay, sobre el arroyo Chacabuco (Figura 3B). ${ }^{5}$ En términos de las características constructivas se ha descripto como una construcción de dos cuadros oblicuos foseados y con parapeto de $50 \mathrm{~m}$ y se menciona un rancho de $4 \times 5 \mathrm{~m}$. También se halla la referencia al uso de cueros para las cabañas, se describen unos 129 individuos, 250 caballos, y 200 mulas. Los materiales mencionados para la construcción son: cueros, paja, ciprés y chacay, de disponibilidad local y fácil edificación (Informe de Nicolás Palacios de marzo de 1883, en Viejobueno 1883). En las fuentes es clara la modificación intensiva del espacio a partir de la construcción de infraestructura para las necesidades de resguardo, almacenamiento, alojamiento,

\footnotetext{
4 Para más información sobre los relevamientos Encina y Moreno, en particular sobre los álbumes fotográficos que acompañaron el relevamiento, ver Rodríguez Aguilar y Vezub (2017) y Butto (2017). 5 Expediente asociado (DV 65: Pp. 873) al mapa de Carlos Encina y Edgardo Moreno de 1884 (D V.1 P424. Sección XXXI al XXXIII. n IV (1-5). Departamento Gestión Documental de la Dirección Prov. de Catastro e Información Territorial de Neuquén.
} 


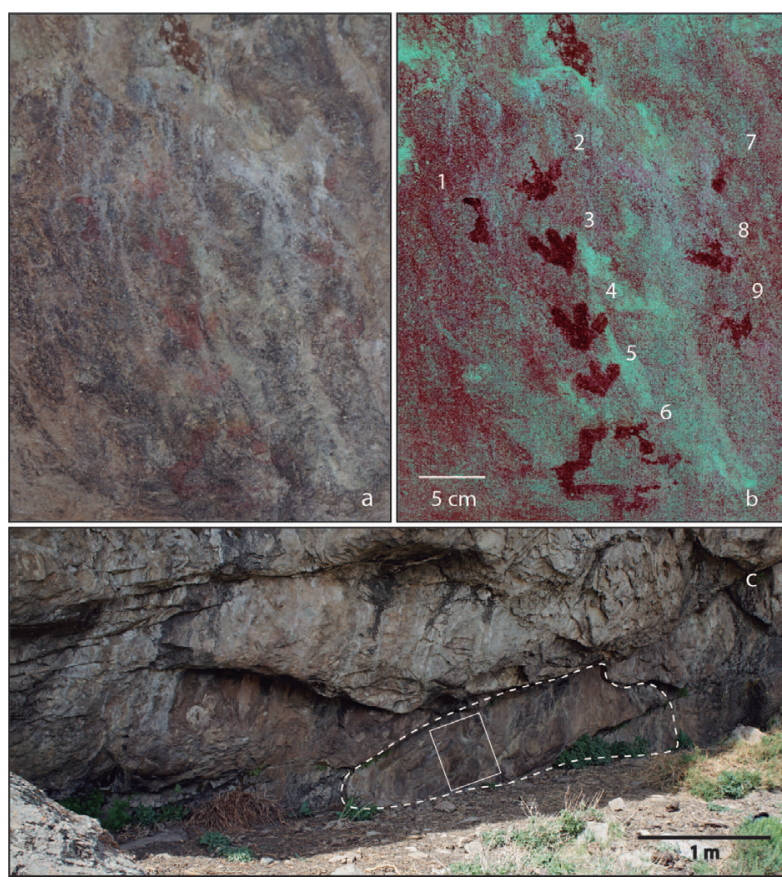

Figura 5. Sector Cerro Chacabuco. Alero 2. Izquierda: Imagen de aproximación a las pinturas rupestres; Derecha: imágenes resaltadas mediante el filtro YRE, del plug-in DStretch. Abajo: vista general del alero, con el panel y el sector con las pinturas.

Figure 5. Cerro Chacabuco sector. Alero 2. Left: Approach image of the cave paintings; Right: images highlighted by the YRE filter using DStretch plug-in. Bottom: general view of the shelter, and the paintings.

establos y corrales -plasmando jerarquías militares en la organización espacial-.

Al evaluar los principales procesos de formación que podrían estar afectando el sector, no hay alteraciones masivas de terreno actual que impacten en el registro subsuperficial, como edificaciones, rutas o canteras. Por el contrario, a nivel superficial, la depositación de cenizas de grano muy fino en toda la zona ha generado una cobertura masiva que dificulta la visibilidad en toda el área. El curso del arroyo Chacabuco tampoco parece haberse modificado, es evidente la colonización del curso por el sauce. Es importante destacar la visita, reclamación y recolección de restos constructivos y materiales arqueológicos durante la ocupación inmediatamente posterior -estancia flia. Newbery y Jones-, la construcción de caminos y la escuela rural, aunque, no se han podido conocer colecciones particulares en la zona.

En términos de expectativas, podemos esperar estructuras someras enterradas por la dinámica de acumulación y depositación de cenizas, rasgos negativos -fosos y postes-, alteraciones en los sedimentos como las zonas de corrales y la dispersión de materiales asociados a la ocupación militar. Se suman las evidencias sobre la reutilización de este espacio por parte de propietarios de las estancias y poblaciones criollas, durante la primera mitad del siglo $X X$.
En las prospecciones superficiales realizadas en ese sector, más allá de la alta cobertura del suelo por presencia de cenizas y la consecuente baja visibilidad arqueológica, no se detectó ningún rasgo ni materiales en superficie (Figura 3B y C). Sumamos también un análisis exploratorio mediante teledetección (Banda $\mathrm{L}$ del Saocom 1A) que consistió en un análisis visual de imágenes de doble polarimetría, análisis de texturas y PCA para detectar anomalías en la zona. ${ }^{6}$ El análisis no pudo completarse ya que en el momento no había imágenes QuadPol para adquirir en el área, y la resolución de las imágenes obtenidas resultó grande (Hadjimitsis et al. 2020; Lasaponara y Masini 2013). No obstante, estas limitaciones, se seguirá evaluando la adquisición de imágenes de mayor resolución en el futuro. Es importante destacar que hay registros orales sobre la colecta y reutilización de materiales en el pasado, mientras que hoy en día el sector dada su cercanía a la ruta, es de muy fácil acceso y visibilidad (Figura 3B).

\section{Sector Centro-Norte}

Este sector linda con la RN 237 y se caracteriza por depósitos morénicos con relieves de poca pendiente ubicados en diferentes niveles aterrazados. El nivel superior presenta mallines, una laguna temporaria y bloques erráticos compuestos por rocas intrusivas. Los cerros que se disponen en dirección NE-SO, presentan aleros y arroyos que desaguan hacia el río Limay. Estos rasgos geomorfológicos son especialmente atractivos para la ocupación humana por su orientación Norte, espacios de reparo, cercanía a los recursos vegetales y cursos de agua. Se han detectado dos sitios arqueológicos y un alero sin evidencias superficiales de uso; en las prospecciones superficiales no se identificaron materiales arqueológicos.

La Cueva 2 se emplaza en un afloramiento tobáceo a unos $600 \mathrm{~m}$ de la RN 237, en la margen Norte de un arroyo. Es una oquedad de gran tamaño, con doble entrada -Este y Oeste-, rodeada de un bosquecillo de Chacay, previamente reconocida por el Lic. A. Hajduk (Figura 3E). Su entrada Este, es amplia, de 2,1m aproximadamente de altura máxima. El espacio interno (Figura 3E), también muy amplio, presenta su lado Sur cubierto por grandes bloques desmoronados del techo de la cueva, y su lado Norte, mide aproximadamente $6 \mathrm{~m}$ de largo. Si bien no se observaron representaciones rupestres, sí había materiales arqueológicos en superficie-cerámicas, huesos termolterados y material lítico-, que fueron fotografiados y registrados in situ (Figura 4B). En el interior se registraron escasa vegetación y evidencias de ganado -bosteo- en superficie. Por su visibilidad y accesibilidad presenta alto riesgo de posibles perturbaciones. A unos $30 \mathrm{~m}$ se halló un afloramiento basáltico -la disyunción columnar del

6 El Nivel de Procesamiento fue Single Look Complex (SLC), Nivel $1 \mathrm{~A}(\mathrm{~L} 1 \mathrm{~A})$, datos complejos en rango oblicuo -slant range-calibrados radiométricamente sin correcciones geométricas. 
basalto se observa en planos horizontales-, en el cual no se hallaron materiales arqueológicos ni representaciones rupestres.

El Alero 3 se localiza sobre un afloramiento en un cerro a unos $900 \mathrm{~m}$ de altura, es un paredón con orientación NNE, bastante escarpado, sin proyección de techo, pero con reparo efectivo a los vientos predominantes (Figura 3F). Presenta una explanada de $15 \mathrm{~m}$ de largo y 1,5 de ancho. No se observan representaciones rupestres -ni soporte apto para ellas. Se hallaron en una oquedad de la pared, tres fragmentos cerámicos y una lasca (Figura 4C), depositados intencionalmente para resguardo, se verificó la presencia de ganado y evidencias de actividad humana.

El extremo Norte del sector se caracteriza por presentar cerros altos en dirección E-O, y el mallín Frisón en el fondo de un valle que se extiende hacia el Norte por fuera de los límites de la estancia. El extremo Noroeste de la estancia intercepta esta unidad ambiental y allí discurren una serie de cursos de agua estacionales que concentran rodados de diversas rocas disponibles regionalmente, algunas de excelente calidad para la talla. Las prospecciones se focalizaron sobre la cara Este del mallín Frisón, en consonancia con los límites territoriales de Ea FC. En el área se observaron afloramientos rocosos con pendientes algo abruptas sobre las que descienden pequeños cursos de agua estacionales y en ningún caso se constató la presencia de material arqueológico. En la parte alta de estos cerros, se observó y mapeó la presencia de bloques erráticos de distintos tamaños, algunos de envergadura considerable, que ofrecen buen reparo a los vientos del Oeste, predominantes en el área, pero sin evidencias arqueológicas detectables. En el extremo Sureste del mallín, se detectó un afloramiento rocoso, con una pequeña cueva y un reparo orientado hacia el Norte, donde tampoco se observaron evidencias arqueológicas. En la parte alta de este cerro, se registró la presencia de bloques partidos de vidrio volcánico, de calidad regular para la talla.

Más al Sur se ubican los arroyos Frisón y Newbery, que corren encajonados. Las pendientes abruptas y de altura no han arrojado resultados positivos de presencia arqueológica. Se hallaron locus de reparo que podrían haber sido utilizados, así como fuentes de materias primas líticas. En términos generales, presenta una menor exposición a factores de deterioro antrópico como baja accesibilidad, ausencia de sectores de uso público y sólo una huella vehicular.

\section{Señal arqueológica de la Estancia Fortín Chacabuco}

Para representar la señal arqueológica en esta escala microregional, elaboramos un mapa comparando variables geoambientales como son la exposición NorteEste-orientación de la pendiente correspondiente al Norte y al Este a partir de un Modelo Digital de Elevación de 5 metros de resolución (fuente IGN)-, cota de 900 (msnm) -la altitud se extrajo del mismo MDE-, exposición a vientos predominantes del Oeste -velocidad promedio anual (m s -1) extraída de la base de datos climática WorldClim 2.1. Las capas restantes son resultado de los relevamientos propios: área buffer de los cursos de agua $(250 \mathrm{~m})$, la presencia de sitios, los reparos potenciales y los afloramientos rocosos -posibles fuentes de materias primas como obsidiana y basalto principalmente (Figura 6)-.

Un primer análisis espacial muestra que la presencia de sitios se asocia a las unidades del paisaje más estables, es decir, a los sectores montañosos y los valles asociados. En cambio, los sectores geomorfológicamente más activos, como las planicies de inundación activas e inactivas de los grandes cursos de agua -río Limay y arroyo Chacabuco- no han arrojado, hasta el momento, evidencias arqueológicas. Los sectores con mayor dinámica ambiental tienen un menor potencial de preservación de sitios y evidencias arqueológicas, a esto debe sumarse, que estas planicies son también las que presentan mayor cobertura por las cenizas del volcán Puyehue (2011), limitando la visibilidad completamente.

En líneas generales, la totalidad de los contextos hallados se encuentran espacialmente vinculados a cursos de agua, permanentes o estacionales, en todos los casos en localizaciones a menos de 250 metros de una fuente de agua. Como se observa en otros sectores de los andes norpatagónicos (Barberena 2013, Gordón et al. 2019; Scartascini et al. 2020), los sitios documentados en la Ea. FC se emplazan en un área de tránsito entre el bosque y la estepa, en sectores con orientación NorteEste, a sotavento de los vientos predominante del Oeste y con las mejores condiciones de luz natural, siendo además los sectores altos -mayores a 900 msnm- los más frecuentemente utilizados (Figura 6).

En base al análisis presentado, se observa que las poblaciones humanas no dieron un uso homogéneo al paisaje en la Ea FC. Los datos preliminares muestran la elección de determinados espacios en función de la localización, acceso a recursos y orientación. Sin embargo, no todos los sectores que reúnen estas condiciones "óptimas" fueron utilizados. Dos contextos relevados en el sector Centro-Norte presentan condiciones análogas a otros sitios documentados en la estancia -e.g. reparo, cercanía a cursos de agua- pero no arrojaron evidencias positivas respecto al hallazgo de material arqueológico en superficie -deberían ser evaluados en estratigrafía. Llama la atención, además, la ausencia de sitios potenciales y materiales arqueológicos aislados asociados y/o emplazados en ambientes de alta bioproductividad, como son los mallines.

Respecto a la temporalidad de la ocupación humana en 


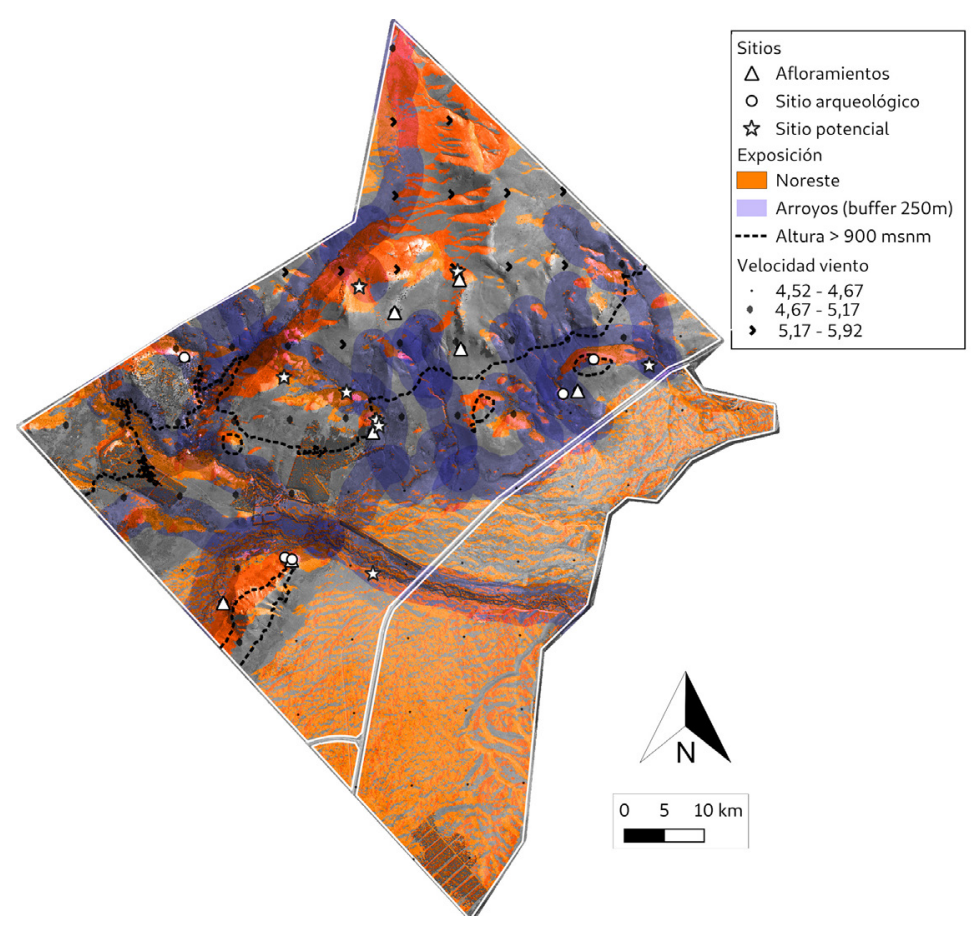

Figura 6. Mapa potencial arqueológico de la Ea. FC.

Figure 6. Map of archaeological potentiality of the Ea. FC. la Ea FC, los datos iniciales y los indicadores temporales disponibles -cerámica, cuentas vítreas, motivos en el arte rupestre- sugieren cronologías tardías, es decir posteriores a ca. 3000 años AP. Sin embargo, hasta el momento, no se obtuvieron fechados absolutos, lo que permitirá, en el futuro, afinar la resolución temporal de la ocupación humana de este sector.

Al analizar las pinturas rupestres del sitio Alero 2 dentro del marco regional, surgen algunas observaciones relevantes. En primer lugar, el sitio se emplaza entre diversos contextos rupestres bien caracterizados y diferenciados. Hacia el Oeste en el ambiente boscoso y lacustre del Lago Nahuel Huapi, el arte rupestre ha sido caracterizado con una modalidad estilística ad hoc denominada Modalidad del ambiente boscoso y lacustre (MABL), con una cronología de no más de 1000 años AP (Albornoz y Cúneo 2000). Esta modalidad se caracteriza por la presencia de motivos pintados y rojos, de formas geométricas simples y sencillas sin demasiado rigor geométrico, así como también una amplia variedad de motivos figurativos como cuadrupedos, jinetes y la baja incidencia de motivos como pisadas. Por otro lado, en las cercanías del sitio y hacia el Noroeste, en el ambiente de ecotono-estepa, el arte rupestre de la cuenca media y alta del río Limay y la del lago y río Traful plantea la coexistencia de al menos dos estilos, el de pisadas y el de grecas (Ceballos 1982; Crivelli 2006; Fernández 2006, entre otros). En cuanto al primero, se destaca por la profusa producción mediante la técnica de grabado, y con una cronología relativamente ajustada no superior a los 3000 años AP. El estilo de grecas también conocido como tendencia abstracta geométrica compleja (Gradín 1988), en cambio, no superaría los 1000 años. En la zona de Traful y cercanías, se destaca la importante presencia de motivos figurativos, policromía y combinación de técnicas, tal como se constata, por ejemplo, en el sitio de Malal Huaca o Mala Vaca (Bruch 1902; Schobinger 1956) aspecto que lo diferencia notablemente de los contextos antes descritos. Finalmente, los numerosos sitios de la estepa rionegrina muestran estilos de pisadas y de grecas, y otras posibles construcciones estilísticas (Boschín 2009; Llamazares 1989, entre otros). En suma, se puede plantear que el sitio Alero 2, si bien resulta discreto en términos de la cantidad de motivos, puede ser considerado relevante dentro del contexto rupestre regional, ya que no sólo posee motivos vinculados con los estilos tradicionalmente definidos para Patagonia, sino que también podría incluirse como perteneciente a una modalidad de producción rupestre norpatagónica (Llamazares 1989), que hasta la actualidad constituye una problemática no saldada dentro del ámbito académico.

Por su parte, la presencia militar de FC en términos arqueológicos, difiere de la ocupación indígena de larga profundidad temporal en la zona. Es necesario contemplar en primer lugar, que implicó la discontinuidad en las ocupaciones indígenas en el área, a partir de la relocalización y matanza producidas por el avance militar. Por otra parte, la duración del FC fue de fines de 1882 a principios de 1884, el uso intensivo de los sectores asociados al arroyo difiere tanto en los reparos elegidos históricamente por las poblaciones indígenas, como en las formas de ocupar ese espacio y la cultura material asociada. Como mencionamos, no se hallaron evidencias de rasgos ni materiales en superficie suficientes para profundizar en las características del fortín desde las evidencias arqueológicas. No obstante, en el futuro será posible profundizar las tareas de prospección iniciadas a partir de diferentes líneas de 
trabajo (teledetección, sondeos y excavaciones y revisión de colecciones privadas, entre otras).

Además de la detección de sitios arqueológicos, las tareas de prospección permitieron identificar otros rasgos relevantes en el paisaje. Se registraron diversos sectores con afloramientos de rocas aptas para la talla. Asociado al sector del Cerro Chacabuco se determinó la presencia de rocas volcánicas de grano fino oscuro, con fractura concoide. Además, se documentó la presencia de vetas o venillas de vidrio volcánico en diversos sectores de la zona central de la estancia. En este caso, si bien sólo se recuperaron fragmentos muy meteorizados, la presencia de estas rocas puede tener relevancia a nivel regional (Boschín y Massaferro 2014) e invita a profundizar la exploración de estos depósitos y a caracterizar sus propiedades físicas y químicas.

Se recuperaron y registraron escasos desechos de talla lítica, de diversas materias primas locales -rocas de grano fino oscuro- y no locales -variedades de sílice-, además se recolectaron varios fragmentos de tiestos cerámicos correspondientes principalmente al cuerpo de pequeñas vasijas -en cueva 2 y alero 3 . El análisis preliminar indica similitud con los materiales cerámicos usualmente recuperados en la región, es decir alfarería utilitaria de producción local, con poca o nula decoración.

Asimismo, se recuperaron restos óseos de diversas especies faunísticas, en su mayoría modernas. Las muestras presentan especies autóctonas e introducidas, con marcada evidencia de exposición y re-exposición superficial, como así también una importante actividad de carnívoros sobre el conjunto. Esto permite inferir la posible depositación actual y natural de los materiales. Por otra parte, los restos humanos hallados y las cuentas vítreas también presentan evidencias de la dinámica de re-exposición y la posible modificación del contexto por parte de diferentes agentes tafonómicos -e.g. remoción por gravedad, acción de carnívoros-, destacando la importancia de preservar la circulación tanto humana como animal en el sector.

\section{Palabras finales}

El diagnóstico de potencial de la Ea. FC articula toda la información relevada, logrando ampliar y profundizar el conocimiento sobre la señal arqueológica de todo el establecimiento. Esta experiencia piloto permitió probar el esquema de trabajo en una escala espacial y de gestión acotada -4.460 hectáreas- para en un futuro extender el estudio a una escala mucho más amplia, como es el PNNH. A su vez, se elaboraron diversos mapas, un informe, un folleto, material de difusión sobre la arqueología, la historia y el manejo del patrimonio cultural de la estancia; se destaca la digitalización y acceso público de documentos del Museo de la Patagonia-PNNH. Finalmente, a partir del trabajo integrado e interinstitucional, se ha generado un conjunto significativo de información en una de las áreas de vacancia del Plan de Gestión del PNNH 2020, incorporando el patrimonio cultural como unos de los valores de conservación del Plan de manejo de Ea FC, lo que permitirá en el futuro diseñar agendas de investigación históricas y arqueológicas más específicas

Bariloche, 31 de marzo de 2021

\section{Agradecimientos}

Agradecemos a los y las integrantes de la administración del Fortín Chacabuco-TNC, especialmente a Gustavo Iglesias, Gwen Hulssegge y Nicolás Rodríguez; y al Lic. Horacio Paradela, Intendente del PNNH. Al grupo de profesionales que nos han asistido Dra. Florencia Bechis, el Dr. Juan Falco, el Lic. John Ballesteros y la Lic. Josefina Schweciakrdt (IIDyPCa-UNRN-CONICET), Camila Burguburu y Nicolás Tanos (Sede Andina, UNRN). También colaboraron la Dra. Solange Fernández Do Río, Dra. María Andrea Nicoletti, Dr. Walter Delrío, Dr. Donaldo Bran, vet. Fernado Raffo, Dr. Marcos Easdale, Dr. Héctor del Valle y Dra. Ana Butto. Especialmente al personal del Museo de la Patagonia, al Técnico Eduardo Pérez Navarro, Gdpque. Eduardo Morgenstern y Rafael Taubensclag. Este proyecto se financió con el subsidio PIDTT 40-B-694: "Diagnóstico de Potencial Arqueológico de la Estancia Fortín Chacabuco (PNNH-APN)" dirigido por los Dres. M. Bianchi Villelli y F. Scartascini. Tuvo como marco también el proyecto PUE CONICET 2018-2023 dirigido por la Dra. C. Briones.

\section{Bibliografía}

Administración de Parques Nacionales (APN). (2001). Reglamento para la Conservación del Patrimonio Cultural en Jurisdicción de la APN. Resolución HD $115 / 01$.

Administración de Parques Nacionales (APN). (2019). Plan de gestión del PNNH. 2019-2029. https://www. nahuelhuapi.gov.ar/plangestion.html

Albornoz, A. M. y E. Cúneo (2000). Análisis comparativo de sitios con pictografías en ambientes lacustres boscosos de Patagonia Septentrional. Arte en las Rocas. Arte rupestre, Menhires y piedras de colores en la Argentina. Buenos Aires: SAA y AAINAPL (pp. 163-174).

Albornoz, A. M. y A. Hajduk (2006). El área del Nahuel Huapi: 10.000 años de historia. Patagonia Total, Antártida e Islas Malvinas (pp.63-75). Buenos Aires: Ediciones Barcel Baires, Centro Literario Alfa.

Albornoz A. M. y A. Hajduk. (2008). "Ladran sancho" jinetes y caballos en el arte rupestre en la arqueología y la etnohistoria del área del Nahuel Huapi. XII Jornadas Interescuelas. (CD). 
Arias Cabal, P., A. Hajduk, E. Crivelli, A. Chauvin, A. M. Albornoz, Á. Armendáriz Gutiérrez, S. Caracotche, M. Cueto Rapado, M. Fernández, P. Fernández Sánchez, M. J. Lezcano, E. Palacio Pérez, J. Tapia Sagarna, M. Tammone, L. C. Teira Mayolini y J. Vallejo Llano. (2011). Informes y trabajos. Excavaciones en el exterior. pp:1942 Madrid.

Bandama, F., C. Shadreck, S. Hall y C. Tinguely. (2018). Measly but motley and manifest: The typological and chemical characterisations of glass beads from the Southern Waterberg, Limpopo Province of South Africa. Journal of Archaeological Science: Reports 18:90-99.

Bandieri, S. (2012). Más acá del Colorado. Historia regional y relaciones fronterizas en la Norpatagonia argentina. Nuevos Mundos Mundos Nuevos 7:1-25.

Barberena, R. (2013). Biogeografía, competencia y demarcación simbólica del espacio: modelo arqueológico para el norte de Neuquén. Intersecciones en Antropología 14: 367-381.

Behrensmeyer, A. (1978). Taphonomic and ecologic information from bone weathering. Paleobiology 4 (2): 150- 62.

Bessera, E. (2008). Políticas de Estado en la Norpatagonia Andina. Parques Nacionales, desarrollo turístico y consolidación de la frontera. El caso de San Carlos de Bariloche. (1934 - 1955). Tesis de Licenciatura en Historia, Ms.

Bianchi Villelli, M. y F. Scartascini. (2020). Informe final: Diagnostico del potencial arqueológico de la Estancia Fortín Chacabuco (PNNH-APN). Ms.

Blanco, G. (2012). El paisaje patagónico en el cambio de siglo: tierra, ganado y productores en el avance de la frontera productiva. Anuario 24:149-167.

Boschín, M. T. (2009). Tierra de hechiceros: arte indígena de Patagonia septentrional argentina. Córdoba: Ediciones Universidad de Salamanca.

Boschín, M.T. y G.I. Massaferro (2014). La obsidiana: una señal geoarqueológica del alcance de las relaciones sociales en la Patagonia Pre y Post-Hispánica. En Arqueología Precolombina en Cuba y Argentina: Esbozos desde la Periferia, editado por O. Hernández de Lara y A.M. Rocchietti, pp. 227-258. Buenos Aires: Aspha.

Bruch, C. (1902). La piedra pintada del arroyo Vaca Mala y las esculturas de la Cueva de Junín de los Andes. Revista del Museo de La Plata 10: 173-6.
Butto, A. (2017). Rastros de violencia en las fotografías de la conquista del desierto (Argentina, 1879-1883). Revista Sans Soleil 9: 59-75.

Bustamante, J. L. y M. J. Saldivia (2018). Atlas de osteología humana: por tomografía computada tridimensional. La plata: Editorial de la Universidad Nacional de La Plata.

Caruso Fermé, L, M. Bianchi Villelli y S. Fernández Do Río. (2018). Los usos coloniales de la madera: primeros resultados arqueobotánicos del sitio Cancha de Pelota Llao Llao" (Río Negro, Argentina). Revista Chilena de Antropología 37: 58-75.

Ceballos, R. (1982). El Sitio Cuyín Manzano. Serie Estudios y Documentos, Centro de Investigaciones Científicas de Río Negro (9): 1-66.

Crivelli Montero, E. A., D. Curzio y M. Silveira. (1993). La estratigrafía de la Cueva Traful I (Provincia del Neuquén). Praehistoria 1: 9-160

Crivelli, Montero E. (2006). Frecuencia de creación de sitios de arte rupestre en la cuenca media y superior del río Limay (Noroeste patagónico). En Tramas en la piedra. Producción y usos del arte rupestre, editado por D. Fiore y M. M. Podestá, pp. 63-74. Buenos Aires: WAC, SAA.

Delrio, W., D. Escolar, D. Lenton, y M. Malvestitti (Eds.) (2018). En el país de nomeacuerdo: Archivos y memorias del genocidio del Estado argentino sobre los pueblos originarios, 1870-1950. Viedma: Editorial UNRN. Recuperado en:https://books.openedition.org/ eunrn/1301

Fernández, M. M. (2006). Cronología del Estilo de Grecas en la cuenca superior y media del río Limay. En Tramas en la Piedra. Producción y usos del arte rupestre, editado por D. Fiore y M. M. Podestá, pp.75-83. Buenos Aires: WAC, SAA, AANAPL.

Fernández, F. J., F. Ballejo, G. J. Moreira, E. Tonni y L. J. De Santis (2011). Roedores cricétidos de la provincia de Mendoza. Guía cráneo-dentaria orientada para su aplicación en estudios zooarqueológicos. Córdoba: SAA y Universdad Sarmiento..

Fernández, P. M., M. Carballido Calatayud, C. Bellelli y M. Podestá (2013). Tiempo de cazadores. Cronología de las ocupaciones humanas en el valle del Río Manso inferior (Río Negro). En: Tendencias teórico-metodológicas y casos de estudio en la arqueología de Patagonia, A. F. Zangrando, R. Barberena, A. Gil, G. Neme, M. Giardina, L. Luna, C. Otaola, S. Paulides, L. Salgán y A. Tivoli (Eds) p.167-175. Buenos Aires: Museo de Historia Natural de San Rafael, SAA, e INAPL. 
Fernández, P., M. Carballido Calatayud, C. Bellelli, P. Tchilinguirián, S. Leonardt y M. Fernández (2019a). Nuevos datos sobre el poblamiento inicial del bosque del centro-Norte de Patagonia, Argentina. Latin American Antiquity 30(2) 300-317.

Fernández, P., M. Carballido, C. Bellelli y M. Podestá. (2019b). Ocupaciones de tiempos históricos en el bosque del centro-Norte de Patagonia. En "Arqueología de la Patagonia: el pasado en las arenas", Pp: 105-116. Puerto Madryn: CENPAT-IDEAUS y SAA.

Furlong, G. (1963). Nicolás Mascardi, S.J. y su CartaRelación (1670). Buenos Aires: Ed. Teoría.

Gordón, F., M. Béguelin, M., D. Rindel, C. Della Negra, A. Hajduk, R. Vázquez, V. Cobos, I. Perez y V. Bernal. (2019). Estructura espacial y dinámica temporal de la ocupación humana de Neuquén (Patagonia argentina) durante el Pleistoceno final-Holoceno. InterSecciones en Antropología 20(1): 93-105.

Gradín, C. J. (1988). Caracterización de las tendencias estilísticas del arte rupestre de la Patagonia (provincias de Río Negro, Chubut y Santa Cruz, República Argentina). Nuevos estudios del arte rupestre argentino. Contribuciones al estudio del arte sudamericano. Boletín SIARB 2: 54-67.

Grayson, D. K. (1984). Quantitative zooarchaeology. Nueva York, Estados Unidos: Academic Press.

Gutiérrez, M. (2004). Análisis Tafonómicos en el Área Interserrana (Provincia de Buenos Aires). Tesis de Doctorado. La Plata: FCNyM, UNLP.

Guzmán, Y. (2009). Viejas Estancias de la Patagonia. Buenos Aires: Claridad.

Hadjimitsis, D., K. Themistocleous, B. Cuca, A. Agapiou, V. Lysandrou, R. Lasaponara, N. Masini y G. Schreier (eds). (2020). Remote Sensing for Archaeology and Cultural Landscapes. Best Practices and Perspectives Across Europe and the Middle East. Springer

Hajduk, A. (1982). Cementerio Rebolledo Arriba, Aluminé, Neuquén. Relaciones de la Sociedad Argentina de Antropología Tomo 14-2: 125-145

Hajduk, A. (1991). Las cuentas vítreas del sitio arqueológico Caepe Malal I (Departamento de Chos Malal, Neuquén) como indicadores temporales. Cuadernos de Investigación, Arqueología y Etnohistoria de la Patagonia Septentrional, editado por M. T. Boschín, pp. 36-48.

Hajduk, A. (2017). Informe sobre antecedentes para Fortín Chacabuco. Entregado a TNC. Ms.
Hajduk, A., A. Albornoz y M. Lezcano. (2006). Levels with extinct fauna in the forest rockshelter El Trébol (Northwest Patagonia, Argentina). Current Research in Pleistocene 23:55-57.

Hajduk, A., A. Albornoz y M. Lezcano. (2008). Arqueología del área del lago Nahuel Huapi. la problemática del uso del medio ambiente boscosolacustre cordillerano y su relación con el de estepa y ecotono vecinos. III Jornadas de Historia de la Patagonia. UNCO. CONICET. Historia de la Patagonia: 3eras Jornadas (CD); UNCO, Neuquén.

Hajduk, A., A. Albornoz y M. Lezcano (2011). Espacio, cultura y tiempo: el corredor bioceánico norpatagónico desde la perspectiva arqueológica. En Cultura y espacio. Araucanía-Norpatagonia, compilado por P. Navarro Floria y W. Delrio, pp. 262-292. Río Negro: IIDYPCa- UNRN-CONICET. Recuperado en: http:// iidypca.homestead.com/PublicacionesIIDyPCa/eje_5. pdf

Hajduk, A., A. M. Albornoz, M. J. Lezcano y P. Arias. (2012). The first occupations of the El Trebol site during the Pleistocene- Holocene Transition (Nahuel Huapi Lake, Patagonia Argentina). Current Research in the Pleistocene: 117-120.

Hajduk, A., A.M. Albornoz, M.J. Lezcano y G. Montero. 2013. De Chiloé al Nahuel Huapi. Nuevas evidencias materiales del accionar jesuítico en el gran lago (siglos XVII y XVIII). En: M. Nicoletti y P. Núñez, compiladoras Araucanía-Norpatagonia: la territorialidad en debate. Río Negro: IIDyPCa- UNRN-CONICET.

Hajduk A., F. L. Scartascini, E. Vargas y M. Lezcano. (2018). Arqueología de Isla Victoria, Parque Nacional Huapi, Patagonia Argentina: Actualización y Perspectivas futuras. Intersecciones en Antropología 19 (39:48).

Harman, J. (2008) [2005] Using Decorrelation Stretch to Enhance Rock Art Images. http://www.dstretch.com/ AlgorithmDescription.html

Hernández Llosas, M. I. (1985). Diseño de investigación para representaciones rupestres. En: Programa de Investigación y Documentación de Arte Rupestre Argentino, pp. 9-65. Buenos Aires: Ed. FECIC.

Karklins, K. (2012). Guide to the description and classification of glass beads found in the Americas. Beads Journal 24:62-90.

Kidd, K. y M. Kidd. (1983). A Classification System for Glass Beads for the Use of Field Archaeologist. Proceedings of 1982 glass trade bead conference: 219255. C. Hayes (ed.). New York: III Research Record 16, 
Rochester Museum and Science Center.

Lasaponara, R.y N. Masini. (2013). Satellite Synthetic Aperture Radar in Archaeology and Cultural Landscape: An Overview. Archaeological Prospection 20: 71-78.

Llamazares, A. M. (1989). El estilo "pisadas" en la Patagonia argentina. Análisis de su formulación y algunos datos sobre una posible modalidad septentrional. Boletín 3. SIARB.

López, L.; M. Silveira y C. R. Stern. (2010). Uso de obsidianas entre los cazadores-recolectores en el bosque del lago Traful, Noroeste de la Patagonia, Argentina. Magallania 38(1): 237-245.

Lyman, R. L. (2008). Quantitative paleozoology (Cambridge manuals in archaeology). Cambridge: Cambridge University Press.

Mases, E. (2010). Estado y cuestión indígena. El destino final de los indios sometidos en el Sur del territorio (18781910). Buenos Aires: Prometeo.

Méndez, L. 2010. Estado, frontera y turismo: historia de San Carlos de Bariloche. Buenos Aires: Prometeo.

Molinari, R.; Ferraro, L.; Paradela, H.; Castaño, A. y S. Caracotche. (2000). 2001 Odisea del Manejo: Conservación del Patrimonio Arqueológico y Perspectiva Holística. Ponencia presentada al 2do. Congreso Virtual de Antropología y Arqueología. http://www.equiponaya. com.ar/congreso2000/ponencias/Roberto_Molinari2. htm

Navarro Floria, P. y L. Vejsbjerg. (2009). El proyecto turístico barilochense antes de Bustillo: entre la prehistoria del Parque Nacional Nahuel Huapi y el desarrollo local. Estudios y perspectivas en turismo 18: 414-433.

Oldani, K., F. Pepe y M. Miguel Añon Suarez. (2011). Las muertes invisibilizadas del Museo de La Plata. Corpus. Archivos virtuales de la alteridad americana 1 (1). http:// ppct.caicyt.gov.ar/index.php/corpus

Pérez, P. (2016). Archivos del silencio. Estado, indígenas y violencia en Patagonia Central, 1878-1941. Buenos Aires: Prometeo.

Rodríguez Aguilar, M.I. y Vezub, J.(comp.). (2017). Patrimonios visuales patagónicos: territorios y sociedades. Editado por J. M. Corbetta, A. Savall; fotografías de Pozzo Antonio; Pedro Morelli. CABA. https://issuu.com/ minculturaar/docs/pvp_completo.

Rousaki A., F. E. Vargas, C. Vázquez, V. Aldazábal, C.
Bellelli, M. Carballido Calatayud, A. Hajduk, O. Palacios, L. Moens, P. Vandenabeele (2018). On-field Raman Spectroscopy of Patagonian Prehistoric Rock Art: Pigments, Alteration Products and Substrata. Trends in Analytical Chemistry. https://doi.org/10.1016/j. trac.2018.05.01

Savory, A. (1999). Holistic Management: A New Framework for Decision Making. Washington : Island Press.

Scartascini F. L., F. E. Vargas y A. Bay Gavuzzo (2020). Arqueología y Biogeografía humana en el lago Nahuel Huapi: evaluando el rol del ambiente boscoso-lacustre norpatagónico y su vinculación con la estepa. Revista del Museo de Antropología 13 (3): 251-266.

Schobinger, J. S. (1956). El arte rupestre de la Provincia del Neuquén. Anales de Arqueología y Etnología XXII: 115-227.

Silveira, M. (2003). Las poblaciones prehistóricas e históricas en el área boscosa-ecotonal del lago Traful (provincia del Neuquén). En Actas del III Congreso Argentino de Americanistas, pp. 399-418. Buenos Aires: SAA.

Silveira, M., L. López y G. Pastorino (2010). Movilidad, redes de intercambio y circulación de bienes en el sudoeste del Neuquén (Norpatagonia, Argentina). Los moluscos marinos del lago Traful. Intersecciones en Antropología 11: 227-236

Tapia, A. y V. Pineau. (2013). Tipología, Manufactura y Procedencia de las Cuentas Vítreas de Santiago del Baradero. Cuadernos del Instituto Nacional de Antropología y Pensamiento Latinoamericano - Series Especiales N¹ (3): 105-120.

The Nature Conservancy. (2016). Estancia Demostrativa Fortín Chacabuco. Lineamientos de Manejo. Ms.

Vezub, J. (2009). Valentín Saygüeque y la "Gobernación Indígena de las Manzanas". Poder y etnicidad en la patagonia noroccidental (1860-1881). Buenos Aires: Prometeo.

Vezub, J., y V. Mazzalay (2016). Análisis de redes de parentesco y alianza entre caciques mapuches y tehuelches. Patagonia septentrional, siglo XIX. Redes. Revista Hispana para el Análisis de Redes Sociales 27(1): 81-99.

Viejobueno, J. (1883). Campaña de los Andes al Sur de la Patagonia, por la $2^{\circ}$ División del Ejército, 1883: partes detallados y diario de la expedición. Argentina. Ministerio de Guerra y Marina. Buenos Aires: La Tribuna Nacional. 
Vignati, M. (1936). El asentamiento de la misión jesuita de Lago Nahuel Huapi. Boletín de la Junta Histórica Numismática Americana 8: 315-321.
Vignati, M. (1944). Antigüedades en la región de los lagos Nahuel Huapi y Traful. Notas del Museo de La Plata, Antropología IX (23-29): 53-165. 